\title{
Uptake of Ocular Surgeries at Ebonyi State University Teaching Hospital (EBSUTH), Abakaliki, Nigeria
}

\author{
CG Onyekonwu, MBBS, FMCOphth \\ Department of Ophthalmology, Ebonyi State University Teaching Hospital Abakaliki, Nigeria
}

\section{SUMMARY}

Objective: To ascertain the number, types and frequencies of ocular surgeries done at Ebonyi State University Teaching Hospital (EBSUTH), Abakaliki, with a view to improving the overall surgical uptake.

Methods: A retrospective review of ocular surgeries done at EBSUTH between January 2003 and April 2008 was carried out. Surgical records of all the eye surgeries done and all the surgical diagnoses made were retrieved from the eye operations register in the theatre and the eye clinic register and analysed.

Result: A total of 353 surgeries were done within the period under review. Of these, 312 (88.4\%) with complete data were entered for analysis. There were 183 male (58.7\%) and 129 female $(41.3 \%)$ patients who had surgery, with ages ranging from 6 weeks to 90 years. An annual average of 58.8 surgeries was done. The most common type of surgery done was cataract surgery 147 (47.1\%) of which extra capsular cataract extraction with intraocular lens implant was performed in 121 patients (38.8\%). Others were pterygium excision with anti metabolite application in 58 patients $(18.6 \%)$ and corneoscleral repair in 29 patients (9.3\%). The least performed eye surgeries included incision and drainage of eyelid abscess, $1(0.3 \%)$, exenteration $2(0.6 \%)$; paracentesis oculi $2(0.3 \%)$, and tarsorrhaphy in $2(0.6 \%)$ cases. Trabeculectomy was done in $7(2.2 \%)$ patients.

Conclusion: The yearly surgical uptake at EBSUTH was low and cataract extraction was the most common ocular surgery performed.

Key words: ocular surgeries, analysis, EBSUTH, Abakaliki

\section{INTRODUCTION}

The eye clinic of Ebonyi State University Teaching Hospital (EBSUTH), Abakaliki was revitalized and equipped by the state government in 2003 with basic microsurgical equipment for ophthalmological diagnosis and treatment. Apart from the infrastructural expansion, staff strength was increased to take care of the anticipated upsurge in the number of medical and surgical ophthalmic cases. Clinic days were increased from two to three days per week.

During the sixty-four months which this study covers however, there were several national and state industrial strike actions by the labour movement, resident doctors and even nurses. In 2006, the main theatre in which eye surgeries were done was gutted by fire. An emergency theatre was arranged where eye surgery was allotted theatre use once monthly initially, then one day in a week, until early 2008 when the theatre was finally refurbished. These factors, in addition to patient-related causes such as costs of treatment and ignorance of availability of tertiary eye care services, have contributed to increased surgical uptake including cataract and glaucoma at the centre.

Cataract remains the world's leading cause of blindness ${ }^{1}$ with about 16 million cases, ${ }^{2}$ whereas glaucoma has been estimated by the World Health Organization to have caused blindness in 5 million people. ${ }^{3}$ It is the second most prevalent cause of blindness after cataract. Blindness is more rife in developing countries than in developed nations and the need to increase access to surgery in many of the tertiary eye centre is generating concern among eye care personnel in Nigeria.

Increasing the surgical productivity of existing ophthalmologists will reduce the backlog of cataract surgeries. ${ }^{4}$ Most studies carried out in Nigeria, ${ }^{5}$ have identified poor management of ophthalmic theatre time, unstable power supply, and lack of modern ophthalmic operating equipment, personnel and training programmes to upgrade the skills of surgeons as the contributing factors to poor uptake of surgery. However, steps have been taken to improve services through staffing, especially in the areas of power supply and training. A $24 \%$ increase in the total number of ophthalmic surgeries with an increase in cataract surgeries and a relative reduction in trabeculectomies done over 5 years were reported in Ireland. ${ }^{7}$ In the Gambia, the factors affecting the uptake of surgery include treatment costs, lack of information about services, fear, transport difficulties and lack of escorts. The national eye care programme has, however, taken steps to deal with these problems. ${ }^{8}$ 
This study reviews the number, types and frequencies of ocular surgeries at EBSUTH, Abakaliki as a form of situation analysis of the current service uptake and with a view to subsequently make recommendations for improvement.

\section{METHODOLOGY}

Details of all surgical eye operations and all surgical diagnoses within the study period (January 2003 to April 2008) were retrieved from the records entered in the eye operations register in the surgical theatre and the eye clinic register of Ebonyi State University Teaching Hospital, Abakaliki. The age, sex, type of anaesthesia, type of surgery, relative frequency of the surgeries, the month and year in which they were performed and the diagnoses were recorded. The data collected were entered into the computer and analysed using SPSS version 11.0 software.

\section{RESULT}

A total of 353 surgeries were done within the 64-month (5 years and 4 months) study period. Of these, 312 (88.4\%) patients whose data were complete were analysed while those with incomplete data $41(11.6 \%)$ were excluded. A monthly average of 49 surgeries was done (58.8 yearly average).

There were $183(58.7 \%)$ male and 129 (41.3\%) female patients giving a male to female ratio of $1.4: 1$. $\mathrm{P}$ value $=$ 0.155 . The ages of the patients ranged from 6 weeks to 90 years, with a mean age of 43.61 years \pm S.D 22.79 years.

Most of the surgeries, $94(30.1 \%)$, were performed in adults in the age group 46-60 years; the age group 76-90 years had the least number of surgeries, 16 (5.1\%). Fortythree $(13.8 \%)$ children whose ages ranged between 6 weeks and 15 years, also had eye surgery. The age of the patients seemed to have a significant association with the type of surgery. $\mathrm{p}=<0.001$ (table 1 ). Also more males had eye surgery than females.

Table 1. Age group/ sex distribution of patients who had eye surgery

\begin{tabular}{lrrr}
\hline $\begin{array}{l}\text { Age Group } \\
\text { (years) }\end{array}$ & Male & Female & Total \\
\hline 6 weeks-15 & $29(15.8 \%)$ & $14(10.9 \%)$ & $43(13.8 \%)$ \\
$16-30$ & $32(17.5 \%)$ & $23(17.8 \%)$ & $55(17.6 \%)$ \\
$31-45$ & $32(17.5 \%)$ & $24(18.6 \%)$ & $56(17.9 \%)$ \\
$46-60$ & $53(29.0 \%)$ & $41(31.8 \%)$ & $94(30.1 \%)$ \\
$61-75$ & $29(15.8 \%)$ & $19(14.7 \%)$ & $48(15.4 \%)$ \\
$76-90$ & $8(4.4 \%)$ & $8(6.2 \%)$ & $16(5.1 \%)$ \\
\hline Total & $183(100.0 \%)$ & $129(100.0 \%)$ & $312(100.0 \%)$ \\
\hline
\end{tabular}

The leading eye surgery done was cataract surgery in $147(47.1 \%)$ cases; others were pterygium excision with antimetabolite application in 58(18.6\%) cases, corneo-scleral repair in $29(9.3 \%)$ cases, incision and curettage in $14(4.5 \%)$ cases, evisceration in $13(4.2 \%)$ cases and lid surgery in 11 $(3.5 \%)$ cases.

The least performed eye surgeries were incision and drainage of lid abscess, $1(0.3 \%)$ case, tarsorrhaphy $2(0.6 \%)$ cases, paracentesis oculi $2(0.6 \%)$ cases and exenteration in $2(0.6 \%)$ cases. Trabeculectomy was performed in only $7(2.2 \%)$ cases.

Yearly surgical uptake from 2003-2008(first quarter) was: $117(37.6 \%)$ in $2003,47(15.1 \%)$ in $2004,46(14.8 \%)$ in $2005,36(11.6 \%)$ in 2006, $45(14.5 \%)$ in 2007 and $20(6.1 \%)$ in the first quarter of 2008 . Table 2 shows the sex distribution of the patients for the different types of surgery done.

Table 2. Type of surgery / sex distribution

\begin{tabular}{|c|c|c|c|}
\hline Type of Surgery & Male & Female & Total (\%) \\
\hline $\mathrm{ECCE}+\mathrm{IOL}$ & 74 & 47 & $121(38.8)$ \\
\hline ECCE & 4 & 7 & $11(3.5)$ \\
\hline ICCE & 2 & 4 & $6(1.9)$ \\
\hline SICS+IOL & 7 & 2 & $99(2.9)$ \\
\hline Pterygium Excision $+5 \mathrm{fu}$ & 28 & 30 & $58(18.6)$ \\
\hline $\begin{array}{l}\text { Repair of corneo-scleral } \\
\text { laceration incision and } \\
\text { curettage }\end{array}$ & 5 & 9 & $14(4.5)$ \\
\hline Evisceration & 6 & 7 & $13(4.2)$ \\
\hline Enucleation & 5 & 2 & $7(2.2)$ \\
\hline Exenteration & 2 & 0 & $2(0.6)$ \\
\hline Trabeculectomy & 6 & 1 & $7(2.2)$ \\
\hline Excision biopsy & 7 & 3 & $10(3.2)$ \\
\hline Lid surgery & 12 & 2 & $14(4.5)$ \\
\hline Paracentesis oculi & 1 & 1 & $29(0.6)$ \\
\hline Tarsorrhaphy & 1 & 1 & $2(0.6)$ \\
\hline Foreign body removal & 2 & 2 & 491(3) \\
\hline Incision and drainage & 1 & 0 & 190(3) \\
\hline EUA* & 1 & 1 & $2(0.6)$ \\
\hline Total & 183 & 129 & $312(100.0)$ \\
\hline
\end{tabular}

*EUA = examination under anaesthesia

Although, 686 operable cataract cases were diagnosed within the study period, only 147 (21.4\%) cases had surgery performed. About $27.2 \%$ of the cataract surgeries were done in patients less than 45 years, while $75.8 \%$ were performed in patients above 45 years. 
Although 524 cases of glaucoma were diagnosed in the study period, only seven cases of trabeculectomy were recorded. Of the seven cases, $5(71.4 \%)$ were done in adults above 45 years. More than half $(51.7 \%)$ of corneo-scleral repairs were done in children who were 15 years and below.

\section{DISCUSSION}

More males than females had eye surgery within the study period although this was not statistically significant. Consistent with our findings is a recent report that in most hospitals or surgical facilities, males outnumber females. This is primarily due to cultural constraints and does not reflect any biological risk factors associated with males., 10 Furthermore, women are less likely to be educated and more likely to need financial assistance for treatment compared to males.

Surgical uptake was generally low although cataract surgery was the most commonly encountered (extra capsular cataract extraction with intraocular lens implant, 121(38.8\%) was the commonest type). A similar hospital-based study ${ }^{6}$ carried out in Port Harcourt, Nigeria, which recorded more surgical uptake than the present study stated that many eye centres provide cataract surgery for only a small proportion of those that need it due to low demand and inadequate supply of services. Ebonyi State University Teaching Hospital, Abakaliki has encountered some of these hospital and patient-related problems; which apparently contribute to low surgical uptake and the centre is younger with fewer facilities and staff.

Only $21.4 \%$ of patients with operable cataracts had surgery within the period under review. This finding is not markedly different from the report of the study carried out in South Africa which revealed that for a typical Zululand district that had achieved a ratio of one eye surgery to 250,000 residents, eye clinics have been well attended but the surgical services have been underused. It stated that nearly two-thirds of blind or severely impaired residents of Hlabisa with operable cataracts have not had surgery. ${ }^{11}$

Some workers ${ }^{12}$ have also commented that in some locations in developing countries, the facilities are in place but uptake of surgical services is low due to: negative public perception of the surgery owing to poor results, using inadequate or poorly timed treatment, inadequate ophthalmic and anaesthesiology staff, lack of ophthalmic surgical instruments, and poor equipment maintenance. The centre has experienced some of these problems and they may have contributed to the low surgical uptake.

In 2003, Diamond Bank PLC sponsored a cataract surgical outreach programme that increased surgical uptake that year. In 2006, however, the general theatre where eye surgeries were carried out was destroyed by fire and surgeries could not be done for some time. It expectedly affected surgical uptake that year. A new eye theatre was commissioned earlier this year although complementary ophthalmic theatre personnel are still expected.

In this study, the age of the patient was found to have a significant relationship with the type of surgery done $(p=<0.001)$. This may be because cataract and glaucoma, being the leading causes of treatable and preventable blindness, are both age-related. The surgeries for correcting either of the two conditions were commonly done in patients above 45 years. The generally low surgical uptake for cataract and glaucoma could leave the state with an increasing number of visually disabled citizenry, especially the elderly. A population-based study is needed to know the actual prevalence of cataract and glaucoma blindness in the older population in the state and to enable the state government plan for sustainable ocular health services that will eliminate the backlog of cataract surgery and increase the uptake of primary trabeculectomy. Hospital-based studies such as this have limitations and their results cannot be taken to represent the state.

Solutions that will best suit our socio-cultural background must be taken into consideration in the provision of solutions to low surgical uptake as it has been found to constitute a barrier to low surgical uptake in many countries. In India, some of the problems reported are attitudinal barriers, ${ }^{13}$ e.g., patient is too old for surgery, it is God's will, fear of death while the surgery is being performed, could manage daily work and not knowing another person who has had the same type of surgery. Another report from Europe stated that loss of vision to cataract is more prevalent among Black persons, ${ }^{4}$ who are less likely to undergo cataract surgery compared to white persons. ${ }^{15}$ This may be due to multiple factors, including access to health care services, physician bias, and cultural beliefs regarding surgical interventions. Further research is urgently needed to know why surgical uptake in Ebonyi State and Nigeria as a whole is low, especially for cataract and glaucoma surgeries.

Primary trabeculectomy is recommended for people of African origin because glaucoma tends to be more widespread among them. Its symptoms are less conspicuous and patients generally report late to hospitals when the disease is difficult to manage. The disease is more rife in developing countries. ${ }^{3}$ Only $2.2 \%$ of patients seen within the study period had the surgery. There still seems to be a general lack of awareness of this disease in our society, even among the educated. Massive awareness campaigns, screening exercises and glaucoma education in rural communities, such as were done during the recent world glaucoma day celebration across the nation, should be instituted and sustained by the stakeholders. Government should support glaucoma education, research and treatment.

Corneo-scleral repairs were done mostly in children who were 15 years and below. Playing with pointed objects has 
previously been identified as a major source of penetrating injuries in children. ${ }^{16}$ This generally has a worse prognosis than blunt injuries because of lack of the equipment needed to treat multiple organ damages and delay in presentation to the hospital. Parental and care giver education is recommended to increase awareness.

Pterygium excision ranked high among the surgeries that were done. The chronic dryness ${ }^{17}$ and dusty environment in the tropics predispose to pterygium. In addition, Ebonyi State has agricultural and quarry industries and many untarred roads that generate dust that irritates the eyes. The relocation of quarry industries far away from residential areas and the construction of good roads by the government would be helpful.

A study done in Rivers State, Nigeria ${ }^{6}$ showed a $40 \%$ increase in ophthalmic surgery uptake over 10 years. This finding differs from that of our series and in addition our centre is younger. We have not recorded any increase probably because of the challenges the centre has faced. The refurbished eye theatre has just been commissioned and it is hoped that this will contribute to an increase in surgical uptake.

Extracapsular cataract extraction with intraocular lens implants are still done but training is needed for manual small incision sutureless cataract surgery, which is faster with less induced astigmatism. ${ }^{18}$ It is also cheaper than phacoemulsification. With this the centre should be able to contribute to the reduction of cataract in the state. The government has shown some commitment following advocacy visits as one ophthalmologist from our centre was sponsored last year for training in India at Aravind Eye Centre. This surgery is already being performed by the surgeon. Currently, the remaining ophthalmologist are at various stages of learning this procedure. Recently, the centre entered into a working agreement with the Aravind Eye Centre to train all cadres of staff of the ophthalmology department at EBSUTH, to improve efficiency, outcome and uptake. Ebonyi State University administration is responsible for this collaboration and paid the cost for the visit of the three-man team from Aravind. The team visited last December for needs assessment and assisted the ophthalmology department with the cataract outreach programme it organized as part of the team's fact-finding visit. More than fifty surgeries were carried out within two days. Some staff of the department have been selected to be the first batch to undergo training at Aravind Eye Centre, India sometime this year. The university has also donated over 30 million naira to help the department purchase modern surgical equipment such as the Zeiss operating microscope with teaching aids, and diagnostic equipment such as the optical coherence tomography machine (OCT). Plans are underway to start regular eye camps and get sponsorship for them so as to improve surgical uptake. Free cataract outreach programmes have been recommended for regions with huge cataract backlog. ${ }^{19}$ The department carried out an eye outreach programme at a local government headquarters last year at the instance of the chairman of the local government, who we got to purchase a dedicated power generator for use during eye surgeries at EBSUTH. Our nurses in the clinic provide ophthalmic health education to patients before the clinic starts every morning.

\section{CONCLUSION}

Ophthalmic surgical uptake was low at EBSUTH, Abakaliki, however cataract surgeries were the most commonly performed.

\section{REFERENCES}

1. Yorston D. High volume of cataract surgery in developing countries. Eye 2005; 19(10): 1083-1089.

2. Asbel PA, Dualan I, Mindel J, Brocks D, Ahmad M, Epstein S. Age related cataract. Lance 2005; 365 (9459): 550-551.

3. Thylefors B, Negrel AD, Pararajesegaram R, Dadzie KY. Global data on blindness. Bull WHO 1995; 73: 115-121.

4. Thylefors B. The WHO programme for the prevention of blindness and cataract in developing countries. Doc Ophthalmol 1992; 81(3): 330-344.

5. Mpyet CD. An audit of ophthalmic theatre time. J Comm Eye Health 2002; 15(44): 62.

6. Adio AO. A review of ocular surgeries over a ten-year period in the University of Port Harcourt Teaching Hospital, Rivers State, Nigeria. Nig J Ophthalmol 2007; 15(1): 17-21.

7. Long VW, O'Brien CJ. Trends in ophthalmic surgery in Ireland. Ir J Med Sci 2005; 174 (2): 36-39.

8. Johnson JG, Goode SV, Faal H. Barriers to uptake of cataract surgery. Trop Doct 1998; 28(4): 218-20.

9. MwendeJ, Bronsard A, MoshA M, Bowman R, Geneau R, Courtright $P$. Delay in presentation to hospital for surgery for congenital and developmental cataract in Tanzania. $\mathrm{Br} J$ Ophthalmol 2005; 89: 1478-82.

10. Yorston D, Wood M, Forster A. Results of cataract surgery in young children in East Africa. Br J Ophthalmol 2001; 85: 267-71.

11. Rotchford A, Johnson G. Rapid assessment of cataract surgical coverage in rural Zululand. South African Med J 2000; 90: 10301032.

12. Wilson ME, Pandey SK, Thakur J. Paediatrics cataract blindness in the developing world: surgical techniques and intraocular lenses in the new millennium. Br J Ophthalmol 2003; 87:14-19.

13. Dhaliwal U, Gupta SK. Barriers to the uptake of cataract surgery in patients presenting to a hospital. Indian $J$ Ophthalmol 2007; 55:133-6.

14. Munoz B, West SK, Rubin GS, et al. Causes of blindness and visual impairment in a population of older Americans: the Salisbury Eye Evaluation Study. Arch Ophthalmol 2000; 118: 819-825.

15. AGIS Investigators. The Advanced Glaucoma Intervention Study 6: Effect of cataract on visual field and visual acuity. Arch Ophthalmol 2000; 118: 1639-1652. 
16. Umeh RE, Umeh OC. Causes and visual outcome of childhood eye injuries in Nigeria. Eye 1997; 11: 489-95.

17. Kanski JJ. Clinical Ophthalmology. $4^{\text {th }}$ Edition. ButterworthHeinemann Publishers, Oxford, 1999, p. 83.

18. Gokhale NS, Sawhney S. Reduction in astigmatism in manual small incision cataract surgery through change of incision site. Indian J Ophthalmol 2005; 53: 201-3.

19. Mansur MM. Cataract blindness and barriers to uptake of cataract surgery in a rural community of Northern Nigeria. $\mathrm{Br}$ J Ophthalmol 2001; 85(7): 776-780. 